\title{
SOBRE O TRATAMENTO ANALÍTICO DE UM CASO DE AUTISMO: LINGUAGEM, OBJETO E GOZO
}

\author{
Ana Beatriz Freire \\ Elisa Carvalho de Oliveira ${ }^{\star}$
}

\begin{abstract}
Resumo
A partir de fragmentos do caso clínico de uma criança autista, pretende-se, neste artigo, interrogar o saber psicanalítico, em particular, os conceitos de linguagem, significante e objeto. No caso clínico citado, a direção do tratamento se deu pela escuta do analista dos "elementos verbais" apresentados pela paciente, o que propiciou, ao longo das sessões, a construção de um determinado "termo verbal". A hipótese sustentada é a de que esse termo operou, no percurso do tratamento, como algo da ordem de um "significante privilegiado" tal qual formulado por Lacan (1985[1972-1973]). Este termo especifico foi articulado pela paciente, em função de um saber-fazer próprio com a linguagem, ocorrendo não sem uma modalização do gozo, abrindo a possibilidade do surgimento do olhar, na via da construção das bordas corporais.
\end{abstract}

Palavras-chave: psicanálise; clínica; autismo; gozo; significante.

\section{ON THE ANALYTICAL TREATMENT OF A CASE OF AUTISM:}

\section{LANGUAGE, OBJECT AND JOUISSANCE}

\begin{abstract}
Based on fragments of the clinical case of an autistic child, this paper intends to question the psychoanalytic knowledge, in particular, the concepts of language, significant and object. In this case study, the direction of the treatment took place in accordance to the analyst's listening of the "verbal elements" presented by the patient, which resulted, during the sessions, in the construction of a particular "verbal term". The hypothesis supported is that this term has operated, in the course of treatment, as something similar to a "privileged significant" as formulated by Lacan (1985[1972-1973]). This specific term was articulated by the patient, according to her own know-how towards the language, not without a

\footnotetext{
^ Psicanalista, professora do Programa de Pós-Graduação em Teoria Psicanalítica do Instituto de Psicologia da Universidade Federal do Rio de Janeiro, correspondente da Escola Brasileira de Psicanálise, pesquisadora do CNPq, coordenadora da pesquisa Dispositivo Clínico Ampliado: criança e adolescente psicóticos em direção ao laço social e à inclusão escolar. Psicanalítica do Instituto de Psicologia da UFRJ, supervisora no grupo de pesquisa Dispositivo Clínico Ampliado: crianças e adolescentes psicóticos em direção ao laço social. Endereço: Universidade Federal do Rio de Janeiro, Instituto de Psicologia. Av. Pasteur, 250 fundos. Rio de Janeiro, RJ - Brasil. CEP: 22290-240.

E-mail: eco@cosmevelho.com.br
}

$\star \star$ Psicanalista - Escola Letra Freudiana, doutoranda no Programa de Pós-Graduação em Teoria
\end{abstract}


place of jouissance modalization, opening the possibility of the emergence of the look, with the construction of the edges of the body.

Keywords: psychoanalysis; clinic; autism; jouissance; significant.

\section{INTRODUÇÃo}

A partir de fragmentos do caso clínico de uma criança autista, pretendemos interrogar o saber psicanalítico, em particular, os conceitos de linguagem, significante e objeto.

Sobre o saber, Lacan (2003[1967]) distingue o saber referencial do textual. $\mathrm{O}$ saber referencial corresponde àquele sobre o qual se aprende, aquele que é estudado nos textos dos mestres. O saber textual concerne ao saber inconsciente, que vem a ser lido em uma análise e cuja leitura opera transformações na maneira de apreender o saber referencial, de modo a subjetivá-lo. Aprender a partir da psicanálise implica uma relação com o saber, uma relação que assume a falha no saber, falha que Freud no início de sua obra e clínica ${ }^{1}$ detectou ao verificar que seus mestres transmitiram-lhe aquilo que não sabiam.

Assim, seguindo Freud e Lacan, no lugar do não saber, perguntamos: o que a clínica do autismo pode nos ensinar e como, por meio dela, se pode questionar a teoria?

Esses pacientes nos ensinam, primeiramente, que qualquer saber universitário que se quer totalizante, global e a priori é, no mínimo, vão.

Nesta via, propomos pensar a pesquisa em psicanálise não para reparar os impasses com os quais o analista se depara ao longo das sessões com o paciente, o impossível próprio da clínica, mas para aprender com esses impasses, propomos alargar, sem perder a precisão e o rigor, os conceitos da psicanálise, para que um saber-fazer possa ser construído a partir das invenções de cada paciente. $\mathrm{O}$ autismo nos faz questionar os conceitos que acreditávamos estar sedimentados, adquiridos, já como um consenso ou com uma inteligibilidade. Vale, portanto, relembrar o que aprendemos com Lacan sobre e com os autistas.

Em primeiro lugar, assinalamos o que, na "Conferência em Genebra sobre o sintoma", Lacan (1988[1975a]) nos indica que se trataria de saber por que há algo no autista, ou no chamado esquizofrênico, que se congela. ${ }^{2}$ Poderíamos considerar, como hipótese de nosso trabalho, que o algo que se congela, mencionado por Lacan (1975a) estaria referido ao significante Um. Um S1 "congelado", que não faria cadeia e, sendo assim, não cumpriria a função de representar o sujeito para outro significante. No entanto, apesar desse algo que se congela, não se poderia dizer que o autista não fala. $\mathrm{O}$ fato de as pessoas em seu entorno terem dificuldade para escutá-lo, na medida em que os elementos verbais que veiculam (sons, gritos e palavras) não estabelecerem um laço de comunicação com o outro, isso não impede que sejam tratados finalmente, retomemos Lacan (1988[1975a], p. 135), de "personagens sobretudo verbosos". 
Ao abordarmos o termo "verboso", consideramos que este apontaria para uma relação muito singular do autista com a linguagem. Assim, não poderíamos conceber que ele estivesse fora do verbo, mas justamente no verbo onde um gozo a mais se presentificaria como excesso (em função da problemática que se apresenta na articulação dos significantes na linguagem), o que justifica o termo "verboso". Por estarem no verbo, inclusive, constatamos clinicamente que os autistas são passíveis de falar, sobretudo, como observa Maleval (2007), em momentos de devastação.

Em segundo lugar, seria preciso, como nos indica Lacan (1988[1975a]), p. 134), "não nos ocuparmos demasiadamente deles", nem nos colocarmos no lugar do Outro, o que exacerbaria a posição de objeto no qual toda criança se instaura, para podermos escutar o que articulam. Lacan vai mais longe, considera que os autistas "articulam" muitas coisas e que certamente temos algo a lhes dizer. Cabe aqui verificarmos o que eles articulam. Acompanhando-os em suas construções aparentemente bizarras, a proposta de estarmos presentes, mas quase nada - " $a ̀$ peine” - (STEVENS, 2008, p. 25-26), possibilita ao analista direcionar o tratamento para a escuta das construções e invenções apontadas pelo paciente.

Essa situação é bem ilustrada pelo caso clínico de Íris, uma criança autista. Em vez de nos ocuparmos dela, deixamo-nos conduzir por suas vocalizações e movimentos corporais aparentemente sem sentido e pudemos ouvir muitas coisas.

Passaremos agora, a partir de fragmentos do caso clínico dessa paciente, mais especificamente, a analisar o estatuto de um "termo verbal" (LACAN, 1975 b, p. 33) construído pela paciente em determinado momento do tratamento que aqui escrevemos: "Ram". Mais especificamente, objetivamos interrogar em que medida poderíamos considerar esse termo como algo da ordem de um significante privilegiado, que é formulado por Lacan (1985[1972-1973]) acerca do S1, no "Seminário: mais, ainda", livro XX.

\section{2- Fragmento clínico}

A situação em que esta paciente se encontrava, inicialmente, era muito grave, sendo-lhe somente possível emitir sons e gritos indiferenciados, sem estabelecer propriamente uma comunicação com os outros à sua volta. Até aquele momento, a paciente não dirigia o olhar a outra pessoa, era alimentada exclusivamente pela mãe, com alimentos pastosos, e não tinha condições de utilizar o banheiro por conta própria.

Para a realização do trabalho, em torno da singularidade deste caso clínico, tomamos, como uma importante referência teórica, a pontuação feita por Lacan (1988[1975a], p. 134) na "Conferência em Genebra", ao explicitar que, como o nome indica, os autistas "escutam a si mesmos", apontando para um pretenso gozo fechado, que não incluiria o Outro. Para além de si mesmos, insistamos com Lacan, eles escutam muitas coisas, sendo que, em alguns, o fato de escutarem pode, inclusive, desembocar em uma alucinação. Nem todos os autistas escutam 
vozes, mas certamente articulam muitas coisas. Nessa situação, trata-se de ver precisamente de onde escutaram o que articulam, o que denota a possibilidade de algo da ordem de uma alteridade se apresentar para o autista.

Essa marcação de Lacan se constitui em uma baliza importante para abordarmos a clínica do autismo, uma vez que, no caso citado, somente em função da escuta do analista, que tomou as manifestações vocais e motoras da paciente como articulações singulares, foi sendo possível circunscrever uma determinada "atividade" realizada pela paciente ao longo das sessões.

Tal atividade envolvia certa ordem, ou seja, uma articulação, que consistia no fato de Íris "extrair" pequenos pedaços de tinta de alguma mesa, porta, ou ainda de uma parede. Essa "extração", todavia, operava-se quase sempre no ponto específico da superfície onde Íris encontrasse alguma reentrância ou falha. A paciente centrava sua ação no "trabalho" de cavar e recolher o produto de sua escavação, para então jogá-lo longe, emitindo um som como Aaah!, em um dos poucos momentos em que lhe era possível veicular de alguma forma sua voz.

Em determinada sessão, Íris tomou um rolo de papel, mas, dessa vez, para ir até a janela da sala do consultório, onde, tomando o parapeito como um limite, passou a destacar pequenos pedaços de papel, jogando-os não somente para longe, como fazia com os fragmentos de tinta que retirava da parede, mas para fora da sala. Durante essa atividade, Íris passou a emitir novos e diferentes sons.

Com o "contorno da janela", algo da ordem de uma atividade, que podemos nomear como extração de fragmentos de um objeto, anteriormente tão dispersa, passou a ser realizada com "certo enquadramento".

Em uma sessão, na qual se repetia a atividade realizada por Íris na janela, o analista fez uma determinada intervenção expressando que talvez já fosse possível para a paciente deixar um resto do rolo de papel, para retornar o seu trabalho na sessão seguinte. Ao deixar o rolo de papel, e ao se dirigir até a porta do consultório, Íris realizou um movimento, ou melhor, um gesto, e pronunciou um termo construído ou mesmo inventado por ela: "Ram"!. Ao pronunciá-lo, Íris dirigiu ao analista um olhar que, como citado, passou a ocorrer pontualmente e um gesto de aceno.

Neste ponto, consideramos importante mencionar os efeitos dessa articulação do termo "Ram"! sobre os pais de Íris.

\section{Alguns efeitos do tratamento de Íris sobre os pais: o trabalho COM OS PAIS}

Pela primeira vez, nesse momento do processo analítico, os pais dirigiram ao analista uma questão, pois estavam de alguma forma sem saber como agir perante a mudança de posição de Íris, ao passar a falar.

Em uma entrevista com o analista, a mãe diz que foi surpreendente que a filha passasse a se despedir, dando provas de que não só entendia uma separação, mas também a aceitava. Anteriormente, a mãe declarou que, quando se 
afastava da filha, não dizia nenhuma palavra a Íris sobre sua ausência. Essa atitude era determinada pela dificuldade da mãe em supor que a filha sofreria com a separação, mesmo que momentânea, das duas. No entanto, o efeito do afastamento sem qualquer nomeação desse vazio em que Íris era deixada por parte da mãe, fazia com que, ao retornar, encontrasse a filha em um canto do quarto contra a parede, utilizando o único recurso que parecia restar-lhe: a realização de suas estereotipias, em estado agravado.

Os pais, surpreendidos pelo surgimento de um novo termo "Ram", articulado por Íris, e em determinados momentos dirigida, agora, a eles, passaram a sustentar o endereçamento de uma palavra à filha. De início respondendo à despedida da filha e, posteriormente, passando a falar com ela em várias situações do cotidiano, o que promoveu uma mudança de posição de Íris, dado que esta passou a ser considerada não mais como alguém que não falava e que não entendia o que lhe era dito, mas como um ser falante, que se expressava em sua singularidade, e assim alguém a quem, por sua vez, não tão fixada na posição anteriormente ocupada, eles deveriam endereçar palavras.

A seguir, devemos tentar precisar do que se trata quando nos referimos ao termo "Ram" ser considerado no tratamento um significante privilegiado, na via do que é formulado por Lacan (1985[1972-1973]) acerca do S1, uma vez que foi por meio desse termo que se tornou possível, para essa criança, articular algo da ordem de uma fala.

\section{UM SIGNIFICANTE PRIVILEGIADO}

No "Seminário: mais, ainda", livro XX, Lacan (1985[1972-1973]) destaca que a ênfase dada ao significante, em seu ensino, deve-se ao fato de este ser o fundamento da dimensão do simbólico, que só o discurso analítico permite isolar. No enagrama do discurso analítico escrito por Lacan (1985[1972-1973], p. 27), a/ S2 - S(barrado)/S1, o a se escreve em cima à esquerda e se sustenta pelo S2, quer dizer, pelo saber no que ele está no lugar da verdade. É dali que ele interpela o S (barrado), o que deve dar na produção do S1, do significante pelo qual se possa resolver sua relação com a verdade. A verdade procurada é essa, no que diz respeito à lei que regra o gozo.

Temos como hipótese que o que se produz, como efeito do trabalho realizado pela paciente, ao longo das sessões, é justamente algo da ordem de um significante privilegiado. Consequentemente, seria preciso, a partir da experiência clínica, interrogar não apenas que lugar ocupa um significante qualquer, mas interrogar, especialmente, o lugar do significante Um na lógica de uma direção de tratamento.

Assim, podemos considerar que a estrutura como efeito de linguagem é produzida pela impossibilidade de se estabelecer o "Um" da relação sexual - o que é expresso na fórmula "Não há relação sexual" (LACAN, 1985[1972-1973], p. 49). Lacan afirmou " $Y$ a de l' un". Trata-se de uma expressão em francês que poderia ser traduzida por "Há de um Um" (LACAN, 1985[1972-1973], p. 34), em que o partitivo "de um" deve ser mantido para indicar que do conjunto "Um", da unida- 
de, do todo, só se pode extrair uma parte. Pensamos que o partitivo nessa expressão designa, na unidade do suposto conjunto, um paradoxo: referindo-se à filosofia, Lacan, ao designar a unidade do Ser, aponta para o impossível de fazer Um com o ser, de pensar o Um como único, de restituir o Um à sua esfera totalizante.

O S1, como dissemos, não é um significante qualquer, é um significantemestre, que faz valer o "não-todo" na linguagem, na medida em que sua ex-sistência é a condição de possibilidade de articulação significante. O S1 é um significantemestre que singulariza e instaura a ordem significante a partir da qual se encadeiam os significantes, formando uma articulação e um sistema propriamente dito.

Lacan (1985[1972-1973], p.196) profere que o S1 é enxame (essaim). Enquanto é o significante que assegura a unidade de copulação do sujeito ao saber (S1(S1(S1...S2), a noção de enxame interroga o alcance do elemento que não se reduz à unidade, mas comporta os parênteses que produzem o envelope formal da série de significantes Uns, de modo que o sujeito possa vir, aí, a falar. Esse enxame "zumbidor" é o que se apresenta enquanto gozo da alíngua.

Destacaremos, a seguir, o conceito de $\mathrm{S} 1$ articulado à noção de alíngua.Por meio dessa articulação, pretendemos refletir sobre o estatuto da linguagem para o autista. Se, no autismo, não há linguagem propriamente dita como sistema de articulação de significantes, propomos então interrogar como o autismo se serve de alíngua e como ele pode se servir de algo como traço que possibilita ficar no lugar do S1 que, a princípio, não se realizou.

\title{
5. O S1 e ALÍNGUA
}

Para investigarmos ainda a noção de "enxame", o que envolve o gozo d' alíngua, como assinalamos, se faz necessário destacar que o conceito de alíngua toma importância, na obra de Lacan (1985[1972-1973]), porquanto, ao abordar a articulação do sujeito na linguagem, a questão do gozo vem ocupar um lugar primordial.

$\mathrm{Na}$ “Terceira" (1988[1974], p. 9), ao tratar o conceito de alíngua Lacan formula que:

\begin{abstract}
Alíngua é o que permite que o voeu (voto), consideremos que não é por acaso que isso seja também veut (quer), terceira pessoa do indicatio do verbo vouloir (querer); que o nom (não) que nega e o nom (nome) que nomeia, isso também não seja um acaso; nem que d'eux (deles) seja feito da mesma maneira que o algorismo deux (dois), isso não é puro acaso nem arbitrário como diz Saussure. O que é preciso conceber aí é o depósito, o aluvião, a petrificação que se marca pelo manejo, por um grupo, de sua experiência inconsciente.
\end{abstract}

É importante assinalar que, desde a origem, existe uma relação com alíngua. Daí, alíngua merecer ser chamada maternal, pois é pela mãe, ou ainda, por suas palavras, que a criança a recebe e não a aprende. Sendo assim, é certo que 
voltará a surgir logo nos sonhos, em toda sorte de tropeços, em toda sorte de maneiras de dizer, os significantes a partir da maneira pela qual alíngua foi falada e também escutada por cada um em sua singularidade.

Neste ponto destacamos a dimensão do gozo introduzida pelo significante, na medida em que podemos considerar que os significantes Uns de alíngua trazem o "peso" do gozo, do gozo que, aí, nesses significantes, faz depósito.

Ao considerarmos, neste trabalho, a hipótese de que o autismo se configuraria como resposta a um S1 congelado, isto indicaria, em nossa concepção, que esse S1, mesmo que com o estatuto de algo congelado ou mesmo "fixado", não se apresentaria totalmente desvinculado d'alíngua. No entanto, algo se apresentou de tal forma nos primeiros encontros do infans e este primeiro Outro, que se tornou impossível para a mãe, no caso citado, "doar" uma palavra à criança, ou ainda o que foi dito o foi com um gozo excessivo para a criança, fazendo com que fosse problemático, e até mesmo devastador para esta receber essa palavra.

Sobre o Outro, poderíamos dizer, parafraseando a definição lacaniana de angústia (LACAN, 2005[1962-1963]), que o autismo está "não sem" o Outro: ele está sem o Outro enquanto este não se apresenta como Outro da linguagem, tesouro de significantes articulados. Ele tem, entretanto, relação com um Outro inassimilável, isto é, um Outro não extraído de sua plenitude gozante. Este paradoxo, de presença e ausência do Outro, leva-nos a afirmar que mesmo sem o Outro articulado, no autismo, esta ausência de sistema de linguagem não o impede de estar "não sem" o Outro.

Este último Outro se encarna, no caso da pequena Íris, na relação desta com sua mãe, que disse encontrar-se, na ocasião do nascimento da filha, deprimida, morando em um país estrangeiro, onde não havia criado laços afetivos. As únicas pessoas com as quais se relacionava, além do marido e da primeira filha, eram os sogros. Na época, a mãe já queria voltar ao Brasil, mas, em função do trabalho do marido, nem cogitava tocar no assunto.

Durante o parto de Íris, a mãe sofreu uma grave hemorragia e, durante sua recuperação, chegou finalmente, segundo ela, a dizer que preferiria morrer a morar longe do Brasil. A proximidade da morte a levara a formular palavras que estavam silenciadas há muito tempo. Contudo, sobre Íris e seu nascimento, propriamente, nenhuma palavra.

Apesar de o Outro não existir a priori, mas ser uma "elucubração", uma produção do sujeito, a posteriori, de alíngua, supomos que Lacan (1985[19721973], p. 190), ao assinalar a alíngua como dita materna, estaria apontando a presença deste Outro inassimilável muitas vezes veiculado aos significantes maternos e à relação enigmática do lugar que a criança ocupa no fantasma da mãe, ou melhor, entre esta, enquanto encarnando a função de mãe e enquanto mulher. No caso dessa criança, sua posição, inicialmente, apontaria a uma resposta frente aos significantes inassimiláveis, à devastação que a mãe apresentava na ocasião do parto. 
Ao nos perguntarmos sobre a possibilidade do surgimento de um significante privilegiado como efeito do tratamento analítico do autismo, recorremos ao "Seminário: mais, ainda", livro XX (LACAN, 1985[1972-1973]). Nesse Seminário, Lacan escreve que é somente a partir do momento em que algo se desembaraça da materialidade significante em que consiste alíngua, a partir justamente deste algo que lá estava "fixado" (uma vez que, no significante, o gozo faz depósito), que se pode "extrair" de alíngua o que é do significante.

O que, por fim, se indica na fórmula "um significante representa o sujeito para outro significante" (LACAN, 1985[1972-1973], p.194) é que o significante mesmo não é nada definível senão como uma diferença para com outro significante. É a introdução da diferença enquanto tal, no campo do significante, que permite encontrar um princípio de identidade de si para si.

Desse ponto em diante, interrogaremos, inclusive, no caso clínico, em que medida é possível considerar algo que se "destacou" da ordem de alíngua, o termo "Ram", como um significante privilegiado. Será que este termo pode ser considerado um significante privilegiado, tal como formulado por Lacan (1985[19721973]), como algo da ordem do $S 1$ ? Ou, se não tem um estatuto do S1, poderíamos considerá-lo como um significante que já passou por uma negativização de gozo e que, durante o tratamento, não carrega mais a marca absoluta e o caráter de "congelamento"? Esta questão se impõe, pois o surgimento deste significante no tratamento dessa criança vem a produzir efeitos que lhe possibilitaram realizar novas articulações na linguagem, levando-a a formular algo da ordem de uma fala.

\section{O SignifiCANTE-LETRA E O OBJETO $a$}

Com base nos fragmentos do caso clínico mencionado, o termo "Ram" surgiu, primeiramente e em diversas vezes seguidas, no momento em que, ao se despedir no final da sessão, a paciente, ao mesmo tempo, dizia "Ram!" e fazia um aceno, indicando um primeiro esboço do que poderia vir a se articular como um laço ao Outro.

Esse termo, no entanto, passou a ser utilizado por Íris em situações que indicavam que ela havia terminado de beber a água que estava em seu copo, ou que havia fechado a janela, ou mesmo que iria deixar um objeto de lado e iria pegar um outro no armário que ficava na sala do consultório. O que pode ser considerado que ali não se tratava de um significante congelado, ou, ainda, articulado a um único significado, e sim se prestava à possibilidade de novas e diferentes articulações na linguagem.

Neste sentido, faz-se imprescindível que o analista, ao escutar a palavra "Ram!", não tenha dado um significado a priori para essa formulação realizada pela paciente. A intervenção pontual do analista, sustentada num "não-saber orientado" possibilita que Íris se aventure a percorrer a borda do buraco que o significante viria, neste caso, instaurar. 
Assim, para sustentarmos nossas considerações, recorremos, novamente, ao "Seminário: mais, ainda", livro XX, onde Lacan (1985[1972-1973]) formula que pela via da representação não é possível nenhum acesso ao real. É somente no ponto em que se entende o que há de mais vivo ou de mais morto na linguagem, ou seja, "a letra", que algo se circunscreve por ser escrito.

Esta ideia é retomada em “A Terceira”, na qual Lacan (1988[1974]), ao se referir ao S1 como "significante-letra", ressalta que esse significante se escreve fazendo-o sem nenhum efeito de sentido. Ao abordar ainda o conceito de S1 como "significanteletra", Lacan o articula ao objeto $a$, ao formular este significante como: "Homólogo, se ouso dizer, do pequeno objeto a" (LACAN, 1988[1974], p. 6).

Na formulação lacaniana (1988[1974]), o objeto $a$ é aquilo de que não se tem ideia, salvo se ele for quebrado. E, nesse caso, seus pedaços são identificáveis corporalmente como voz, olhar, seio e fezes.

$\mathrm{O} a$, a que Lacan chama de objeto, não é nada mais que uma letra. Em outras palavras, apenas conforme é escrito que o objeto $a$ é extraído, designando um inassimilável que se perde para, inclusive, constituirmos um corpo.

Ao nos referirmos à extração do objeto, podemos considerá-la possível, na medida em que esse objeto é cernido ou cerrado, no centro do nó borromeano. Lacan se serve da articulação do nó de três rodas (de barbante) para escrever o enodamento do Imaginário, do Real e do Simbólico, enodamento este que comporta um buraco no centro.

Dessa articulação do $\mathrm{S} 1$ como homólogo ao $a$, e não como uma relação pontual, biunívoca entre os termos, se faz importante interrogar em que medida o trabalho realizado pela paciente ao longo das sessões, um trabalho que desde sempre trazia a marca da tentativa de uma "extração", propiciou o advento de novas articulações da paciente na linguagem, e se a esse trabalho se articulou a possibilidade do surgimento do olhar dirigido ao analista.

\section{Considerações finais}

No caminho traçado por Freud, diante de seus mestres, ou seja, de um lugar de "não saber", interrogamo-nos o que pode nos ensinar o autismo. Por meio do ensino de Lacan, questionamo-nos, a partir da clínica, em especial de um caso clínico, sobre como podemos alargar os conceitos de linguagem, significante e objeto, para não recuarmos clinicamente diante do autismo.

Ao interrogarmos o estatuto de um determinado termo construído ou mesmo inventado pela paciente, ao longo do seu tratamento analítico, faz-se importante assinalar um vetor na direção do tratamento desse caso clínico que comporta três tempos: 
1) A tentativa de "extração" pela paciente de fragmentos de tinta de parede, seguida de uma determinada vocalização, tentativa esta, escutada pelo analista, como um trabalho ou ainda, uma articulação singular desta paciente na linguagem que apontava à introdução de algo da ordem de um "furo" no que se lhe apresentava como compactado e homogêneo.

2) A realização deste trabalho (de tentativa de "extração") não mais aleatoriamente, mas se utilizando do contorno da janela para jogar para fora da sala do consultório, pequenos fragmentos de um objeto que consistia em um rolo de papel, envolvendo a emissão de novas vocalizações, na via da produção de uma borda de uma escritura.

3) O surgimento do termo "Ram", articulado pela paciente no momento do término de uma sessão, notificado e escutado pelo analista, sem que a este fosse conferido nenhum significado. Segundo nossa hipótese, "Ram" poderia ser considerado como algo da ordem de um significante privilegiado, ou ainda, não tão "congelado", como escrevemos anteriormente, na medida em que foi possível constatar, a posteriori, os efeitos para a possibilidade de essa paciente vir a produzir novas articulações na linguagem, o que se deu no mesmo tempo lógico do tratamento que o surgimento do olhar. A partir do momento em que a paciente passa a olhar para o analista seria possível considerar que "um ponto fora-de-si mesmo" teria sido introduzido. O que nos leva a interrogar sobre a possibilidade de esse objeto (olhar) ter se destacado e se localizado fora do corpo, na via da construção das bordas corporais.

O tratamento do autismo convoca o analista a manter o rigor de sua ética - ética da psicanálise - na escuta do que é da ordem do significante. Podemos considerar que, no autismo, como no caso clínico citado, de início, as poucas articulações na linguagem realizadas pela paciente consistiam na emissão de sons indiferenciados e gritos. No entanto, o analista, em sua aposta ao escutar as manifestações da paciente como algo da ordem do significante ou ainda como "termos verbais", faz valer o essencial da análise, na via da operação do significante mesmo que esta esteja reduzida a não ser, de início, mais do que restos, ou ainda, "elementos verbais".

A clínica do autismo exige, em sua radicalidade, que se questione a teoria a partir da abordagem do real, na dimensão da escritura. Nesta via, apostamos que o termo "Ram", pela função que exerceu para a possibilidade de esta paciente vir a articular algo da ordem de uma fala, no mesmo tempo lógico do tratamento em que surge o olhar, dirigido ao analista, se configuraria com o estatuto de algo da ordem de um significante privilegiado. Talvez pudéssemos considerá-lo, ainda, uma "dimensão da letra" que, ao se escrever, teria tido efeitos para circunscrição do gozo, o que tocaria na posição, anteriormente ocupada pela paciente, que, segundo nossas referências teóricas, poderia ser considerada como "verbosa". 


\title{
Notas
}

\begin{abstract}
1 "A idéia pela qual eu estava me tornando responsável de modo algum se originou de mim. Fora-me comunicada por três pessoas cujos pontos de vista tinham merecido o meu mais profundo respeito - o próprio Breuer, Charcot e Chrobak, o ginecologista da Universidade [...] Esses três homens me tinham transmitido um conhecimento que, rigorosamente falando, eles próprios não possuíam [...] essas três opiniões idênticas, que ouvira sem compreender, tinham ficado adormecidas em minha mente durante anos, até que um dia despertaram sob a forma de uma descoberta aparentemente original" (FREUD, 1980[1914], p. 22-23).

${ }^{2}$ Apesar de considerarmos que nesta passagem Lacan procede à uma aproximação entre os temas do autismo e da psicose, neste momento, contudo, pretendemos nos deter nas questões suscitadas pelo autismo, deixando a problemática posta pela esquizofrenia para um estudo posterior.
\end{abstract}

\section{REFERÊNCIAS}

FREUD, S. A história do movimento psicanalítico (1914). In: SALOMÃO, J. (Org.). Obras Psicológicas Completas de Sigmund Freud. Rio de Janeiro: Imago, 1980. Edição Standard Brasileira. v. XIV, p. 13-82.

LACAN, J. O Seminário: angústia (1962-1963). Rio de Janeiro: J. Zahar, 2005. Livro 10.

LACAN, J. Proposição de 9 de outubro de 1967 sobre o psicanalista da Escola (1967). In: . Outros escritos. Rio de Janeiro: J. Zahar, 2003. p. 248-264.

LACAN, J. O Seminário: mais, ainda (1972-1973). Rio de Janeiro: J. Zahar, 1985. Livro 20.

LACAN, J. Conferencia en Ginebra sobre el síntoma (1975a). Intervenciones y textos, Buenos Aires, v. 2, p. 115-144, 1988.

LACAN, J. Conférences et entretiens dans des universités nord-américaines. Scilicet, n. 6/7, p. 7-62, 1975 b.

LACAN, J. La tercera (1974). Intervenciones y textos, Buenos Aires, v. 2, p. 73 $108,1988$.

MALEVAL, J. C. Objetos soletrados no corpo. Latusa, n.12, p. 69-91, 2007.

STEVENS, A. Aux limites du lien social, les autismes. Les feuillets du Courtil: Publication du Champ freudienne en Belgique, n. 29, janv. 2008.

Recebido em: fevereiro de 2010 Aceito em: maio de 2010 
